\title{
Study of Ag and Au Nanoparticles Synthesized by Arc Discharge in Deionized Water
}

\author{
Der-Chi Tien, ${ }^{1}$ Liang-Chia Chen, ${ }^{2}$ Nguyen Van Thai, ${ }^{2}$ and Sana Ashraf ${ }^{1}$ \\ ${ }^{1}$ Department of Mechanical Engineering, National Taipei University of Technology, 1 Sec. 3, Chung-Hsiao East Rd., \\ Taipei 10608, Taiwan \\ ${ }^{2}$ Institute of Automation Technology, National Taipei University of Technology, 1 Sec. 3, Chung-Hsiao East Rd., \\ Taipei 10608, Taiwan \\ Correspondence should be addressed to Liang-Chia Chen, lcchen@ntut.edu.tw
}

Received 15 June 2010; Accepted 5 September 2010

Academic Editor: Sherine Obare

Copyright ( $) 2010$ Der-Chi Tien et al. This is an open access article distributed under the Creative Commons Attribution License, which permits unrestricted use, distribution, and reproduction in any medium, provided the original work is properly cited.

The paper presents a study of $\mathrm{Ag}$ and $\mathrm{Au}$ nanofluids synthesized by the arc discharge method (ADM) in deionized water. The metallic $\mathrm{Ag}$ nanoparticle $\left(\mathrm{Ag}^{0}\right)$ and ionic $\mathrm{Ag}\left(\mathrm{Ag}^{+}\right)$have played an important role in the battle against germs which are becoming more drug-resistant every year. Our study indicates that Ag nanoparticle suspension (SNPS) fabricated by using ADM without added surfactants exclusively contains the metallic Ag nanoparticle and ionic Ag. Besides that, the ADM in deionized water has also been employed for the fabrication process of Au nanoparticles. The experimental results indicate that the prepared Ag nanoparticles can react with the dissolved $\mathrm{H}_{2} \mathrm{CO}_{3}$ in deionized water, leading to the formation of $\mathrm{Ag}_{2} \mathrm{CO}_{3}$. Significantly different to $\mathrm{Ag}$, the prepared $\mathrm{Au}$ nanoparticles with their surfaces bonded by oxygen are suspended in deionized water by the formation of hydrogen bonded with the neighboring water molecules.

\section{Introduction}

Metal nanoparticles have often been studied and used in nanotechnology. Silver has been used to preserve drinking water from germs since the periods of the Egyptian and Roman empires. It even has been used to preserve milk by putting silver coins in milk since the 18th century by immigrants to America. $1 \%$ of silver nitrate solution has been employed as eye drops to prevent eye disease in newborn since 1884 [1]. In addition, silver foil has also been used to protect wounds from infection since World War I. To preserve the purity of drinking water on a spacecraft, since the 1970s, the National Aeronautics and Space Administration (NASA) has employed containers made from silver for preserving drinking water. However, since the human being overused too many antibiotics over a long time, thus some of bacteria, such as MRSA (Methicillin Resistant Staphylococcus Aureus) [2] and VRSA (Vancomycin Resistant Staphylococcus Aureus) [3] have become resistant to antibiotics. To overcome this problem, the physical and chemical properties of silver have been modified by raising the surface-to-volume ratio [4] of metallic Ag nanoparticles [5], which play an increasingly important role in the battle against germs. A new method in synthesizing Ag nanoparticle suspension (SNPS), the arc discharge method (ADM) [6-9], has been successfully developed. From the experimental results and analysis, it was confirmed that this method was fast, simple, and easily adaptable to mass production. The synthesized SNPS contained the ionic Ag components which increase its germkilling ability [10] and is capable of becoming a major weapon against germs in the postantibiotic era [11].

Similarly, $\mathrm{Au}$ and $\mathrm{Au}$ nanoparticles have been studied aiming at a variety of applications, such as catalysis, biolabeling, nonlinear optical devices, and optical recording media. Producing Au nanoparticles are usually classified into chemical and physical methods. The chemical method usually involves toxic chemicals to be dangerous to the environment. The physical method includes UV and IR radiation, aerosol technology and lithography [12, 13]. The pure Au nanoparticles is successfully produced by using these methods, however they require using some of stabilizer preventing Au nanoparticles from agglomeration. Especially, these methods may remain quite expensive and potentially dangerous for the environment. To resolve this, 
a new method is developed to produce $\mathrm{Au}$ nanoparticles by direct-current (DC) arc discharge in water. During the arc discharge process, when the temperature between electrodes reaches several thousand ${ }^{\circ} \mathrm{C}[14]$, Au wires are etched in the water medium. The vaporized metal can be condensed more efficiently in the dielectric liquid than in a gas phase. Au vapor condensed in water creates a stable $\mathrm{Au}$ aqueous suspension. Well-separated nanosize $\mathrm{Au}$ clusters in pure water can be thermodynamically stable for a long time. This study mainly investigates the suspension mechanism of the prepared $\mathrm{Au}$ nanoparticles and the $\mathrm{Ag}$ nanoparticles.

Some of experimental apparatuses, such as conductivity meters, centrifuges, titrators, and atomic absorption spectrophotometers, have been used to identify and measure the proportion of ionic silver. Similarly, a DC arc discharge system which consists of two Au electrodes, a servo control system, a power supply system, and a glass tank has been used to fabricate the $\mathrm{Au}$ nanoparticles in deionized water.

The rest of the paper is organized in the following order. Section 2 describes the experimental method to fabricate $\mathrm{Au}$ and $\mathrm{Ag}$ nanoparticles. Analysis of the experimental results is presented in Section 3 then followed by conclusions in Section 4.

\section{Experiments}

2.1. Materials. In our experimental setup, silver and Au wires employed as processed materials (Gredmann, 99.99\%, $1 \mathrm{~mm}$ in diameter) are submerged in deionized water $(\mathrm{pH}=6.5$, conductivity $=0.8 \sim 0.9 \mu \mathrm{S}$ ) and used as the electrodes in preparing the $\mathrm{Ag}$ and $\mathrm{Au}$ nanoparticle suspension.

2.2. Experimental System Setup. Figure 1 shows the DC arc discharge system, consisting of four main parts as follows:

(i) two Ag or Au electrodes

(ii) a servo control system used to maintain the distance between electrodes to be constant

(iii) a power supply system employed to control the DC arc discharge parameters

(iv) a glass tank for containing the deionized water and a Teflon electrode holder used to collect the $\mathrm{Ag}$ or $\mathrm{Au}$ colloid

The preparation process of the $\mathrm{Ag}$ and Au nanoparticle suspension by using ADM mainly bases on some of parameters, such as initial voltage, peak current, on- and off-pulse duration, pressure, the gap between electrodes, temperature and volume of deionized water, and fabrication time, as shown in Table 1.

2.3. Identification of $\mathrm{Ag}^{+}$and $\mathrm{Ag}^{0}$. During the arc discharge, both ionic silver $\left(\mathrm{Ag}^{+}\right)$and metallic $\mathrm{Ag}$ nanoparticle $\left(\mathrm{Ag}^{0}\right)$ can be generated. The following apparatuses are used to identify the metallic $\mathrm{Ag}$ nanoparticle and ionic $\mathrm{Ag}$
TABLE 1: Some of key parameters for colloidal Ag production.

\begin{tabular}{lc}
\hline Parameter & Value \\
\hline Initial voltage & $135 \mathrm{~V}$ \\
Peak current & $6.4 \mathrm{~A}$ \\
On-pulse duration & $50 \mu \mathrm{s}$ \\
Off-pulse duration & $50 \mu \mathrm{s}$ \\
Temperature of deionized water & $25^{\circ} \mathrm{C}$ \\
Fabrication pressure & $1 \mathrm{~atm}$ \\
Volume of deionized water & $500 \mathrm{~mL}$ \\
Fabrication time & $60 \mathrm{~s}$ \\
\hline
\end{tabular}

(i) a conductivity meter (JENCO 6307) employed to measure number of ions in the solution and quickly perform qualitative analysis

(ii) a particle sizer (Malvern Instruments ZS-90) used to analyze the distribution of the metallic Ag nanoparticle in suspension: base on this analysis, the velocity and required time can be determined to achieve the optimal conditions for the centrifuge

(iii) a centrifuge (Hettich, Mikro 22R) used to separate the SNPS into particles and ions: inside the centrifuge, particles are precipitated while ionic $\mathrm{Ag}$ is dissolved in water

(iv) a titrator (METTLER TOLEDO-DL50) used to estimate the concentration of the ionic Ag in the solution

(v) an atomic absorption spectrophotometer (Shimadzu AA-680) used to measure the concentration of ionic $\mathrm{Ag}$ below the threshold of $6 \mathrm{ppm}$ and check the accuracy of the estimation made with the above titrator

The conductivity meter was employed to measure the conductivity of the SNPS produced by using ADM and deionized water with a conductivity of $20.1 \mu \mathrm{S} / \mathrm{cm}$ and $0.5 \mu \mathrm{S} / \mathrm{cm}$, respectively. The conductivity of the SNPS was greater than that of deionized water. This indicates that the SNPS contains ions. However, this measure cannot distinguish the type of ions.

In an attempt to explore the nature of ions, ions were then separated from the particles by using a centrifuge and evaluated by a qualitative and quantitative analysis. During the separation process, particles were precipitated while ions were not affected. A disadvantage of this method lies in that it could be impossible to complete the separation process in a short period of time if the particles in the suspension were too small (less than a few nanometers).

To overcome the above problem, the diameter of the SNPS particles was measured first. Figure 2 shows the sizes and size distribution of particles. In the diagram, it can be seen that Ag particles larger than 10 nanometers must be first separated in the centrifuge, in order to remove at least of $96 \%$ the metallic Ag nanoparticles.

The centrifuge used to precipitate Ag nanoparticles was set up with some specific parameters as follows: the radius and rotating speed were $7.5 \mathrm{~cm}$ and $18,000 \mathrm{rpm}$, respectively. 


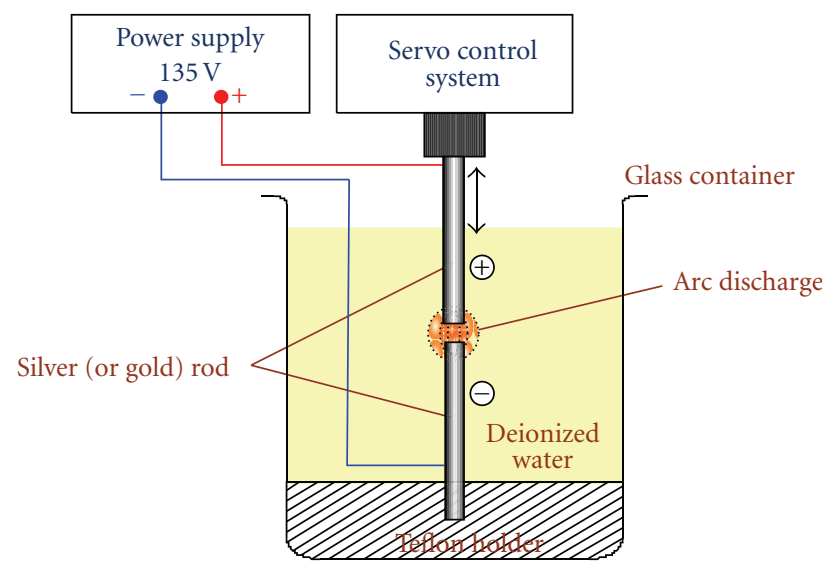

FIgURE 1: The DC arc discharge system.

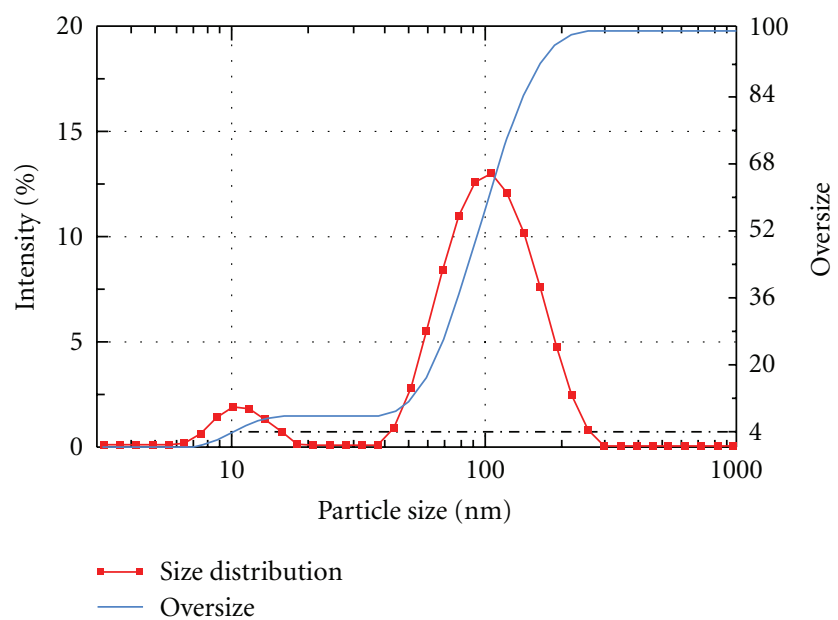

FIGURE 2: Size distribution of Ag nanoparticles.

The relative centrifugal force (RCF) was then calculated by applying.

$$
\mathrm{RCF}=1.118 \times 10^{-5} \times r \times N^{2},
$$

where RCF is the relative centrifugal force $\left(\mathrm{cm} / \mathrm{sec}^{2}\right), r$ is the rotational radius $(\mathrm{cm})$, and $N$ is the rotating speed (revolutions per minute, RPM).

The minimum time so that the centrifuge can separate ions was 100 minutes, which was evaluated by using using Stokes' Law:

$$
V_{s}=\frac{2 \times r_{p}^{2} \times\left(\rho_{p}-\rho_{f}\right) \times \mathrm{RCF}}{9 \eta},
$$

where $V_{s}$ is the particles' settling velocity $(\mathrm{cm} / \mathrm{sec}), r_{p}$ is the Stokes radius of particles $(\mathrm{cm}), \rho_{p}$ is the density of particles $\left(\mathrm{g} / \mathrm{cm}^{3}\right), \rho_{f}$ is the density of deionized water $\left(\mathrm{g} / \mathrm{cm}^{3}\right)$, and $\eta$ is the viscosity of deionized water $\left(\right.$ dyne $\left.\mathrm{sec} / \mathrm{cm}^{2}\right)$.

Figure 3 illustrates the identification process of ionic Ag. First, the ADM was used to fabricate SNPS from deionized water and an Ag rod. A centrifuge (18,000 rpm-100 minutes) was then used to extract the ionic Ag (being contained in the

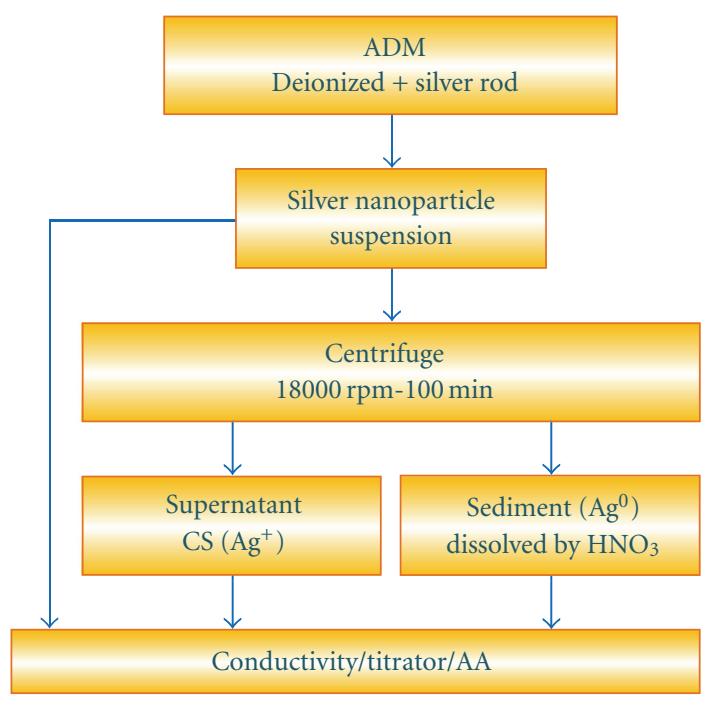

Figure 3: Identification process of ionic Ag.

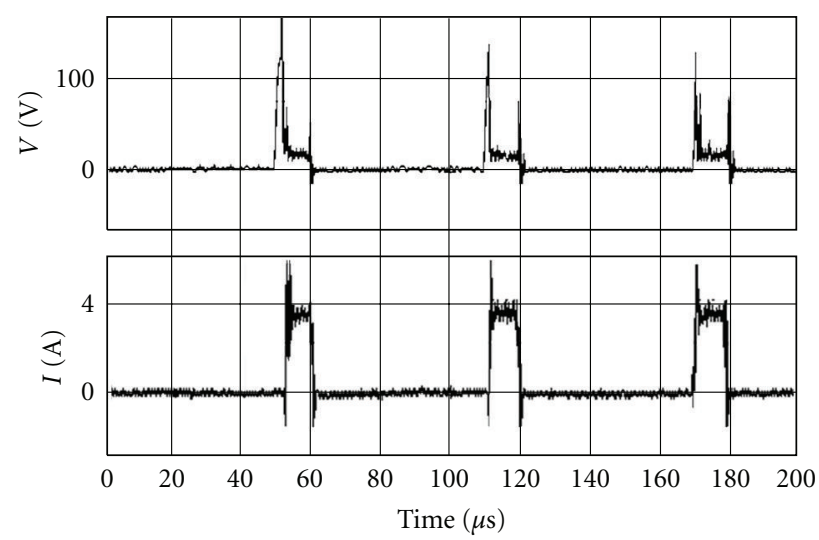

Figure 4: Current and voltage pulses created by the DC arc discharge system during etching of the Au electrodes.

supernatant- $\mathrm{Ag}^{+}$) and the metallic Ag nanoparticles (being contained in the sediment- $\mathrm{Ag}^{0}$ ). The quantitative analysis of the ionic Ag could be directly carried out on the supernatant $\left(\mathrm{Ag}^{+}\right)$. However, the quantitative analysis of the metallic $\mathrm{Ag}$ nanoparticle requires the addition of an appropriate amount of nitric acid $(65 \%)$, so that the sediment $\left(\mathrm{Ag}^{0}\right)$ can be fully dissolved. This mixture is then diluted with deionized water, so that it can be reset to the original volume.

2.4. Fabrication Au Nanoparticles. Au wires were used as the positive and negative electrodes and they would be etched in deionized water if the power supply system provides a stable pulse voltage. To ionize the aqua medium between electrodes and the DC arc discharge with a pulse voltage of around 70$100 \mathrm{~V}$ was first provided within 2-3 $\mu$ s. Following this, shown in Figure 4, a pulse voltage of around $20-40 \mathrm{~V}$ was employed within $10 \mu$ s while the etching current was maintained at $4 \mathrm{~A}$.

The servo control system was based on a close-looped feedback to control the gap between two electrodes (within a 
TABLE 2: Experimental results obtained from fabricating Ag nanoparticles.

\begin{tabular}{|c|c|c|c|c|}
\hline \# & Sample & $\begin{array}{l}\text { Conductivity } \\
(\mu \mathrm{S} / \mathrm{cm})\end{array}$ & $\begin{array}{l}\text { Titrator } \\
(\mathrm{ppm})\end{array}$ & $\begin{array}{c}\mathrm{AA} \\
(\mathrm{ppm})\end{array}$ \\
\hline 1 & Deionized water & 0.5 & 0 & 0 \\
\hline 2 & Colloidal Ag & 20.1 & 19.9 & 26.4 \\
\hline 3 & Supernatant $\left(\mathrm{Ag}^{+}\right)$ & 19.0 & 18.6 & 19.2 \\
\hline 4 & Sediment $\left(\mathrm{Ag}^{0}\right)$ dissolved by $\mathrm{HNO}_{3}$ & $\mathrm{n} / \mathrm{a}^{*}$ & 11.2 & 11.4 \\
\hline
\end{tabular}

* Using $\mathrm{HNO}_{3}$ in order to void the conductivity measurement.

few microns). The upper Au electrode was held by the servo control system while the bottom one was fixed by the Teflon ring. The temperature of deionized water in the tank was maintained at the room temperature.

The surface layer of $\mathrm{Au}$ wires was evaporated and then condensed in water to create the Au suspension. The colloidal Au was then collected. The size distribution, zeta potential, and optical properties of Au particles could be determined through the inspection and analysis of the colloidal Au. A field emission scanning electron microscope (FE-SEM, HITACHI S4700) was applied to determine the size distribution of Au nanoparticles. The Energy Dispersive X-ray (EDX) spectrum was taken to demonstrate the chemical composition of prepared Au particles. A NanoZS90 system (Malvern) was used to measure the zeta potential of the aqueous suspension of the charged Au particles. The measurement of the zeta potential was mainly based on particle velocity in the unit electric field. The double-beam UV-VIS spectrophotometer (9423UVA1002E Helios Alpha) was used to analyze optical properties of Au nanoparticles.

\section{Experimental Results and Discussions}

The experimental results in the fabrication of Ag nanoparticles are shown in Table 2. The difference between the conductivity of SNPS $(20.1 \mathrm{mS} / \mathrm{cm})$ and supernatant $\left(\mathrm{Ag}^{+}\right)$ $(19.0 \mathrm{mS} / \mathrm{cm})$ is insignificant. This suggests that SNPS contains the ions which develop into Ag atoms in the centrifuge and slightly reduce the conductivity of supernatant $\left(\mathrm{Ag}^{+}\right)$.

Shown in Table 2, using the titrator and AA, the concentration of the ionic Ag in SNPS was found at 19.9 and $26.4 \mathrm{ppm}$, respectively. These results prove that ions in SNPS are ionic Ag. The measurement result taken with AA is greater than the one by the titrator since AA is sensitive to both ionic Ag and metallic Ag nanoparticles, whereas the titrator is solely sensitive to ionic Ag.

Because ionic Ag only dissolves in the supernatant, the titrator and AA could be also used to measure the concentration of Ag ions in SNPS. The concentration was identified to be 18.6 and $19.2 \mathrm{ppm}$ by both of the instruments, respectively. There is a slight difference in these measurement results due to the fact that the supernatant $\left(\mathrm{Ag}^{+}\right)$contains less than 10 nanometers of the metallic $\mathrm{Ag}$ nanoparticles.

Similarly, the titrator and AA were used to measure the concentration of the sediment $\left(\mathrm{Ag}^{0}\right)$ which was fully dissolved in nitric acid, in which concentration was identified

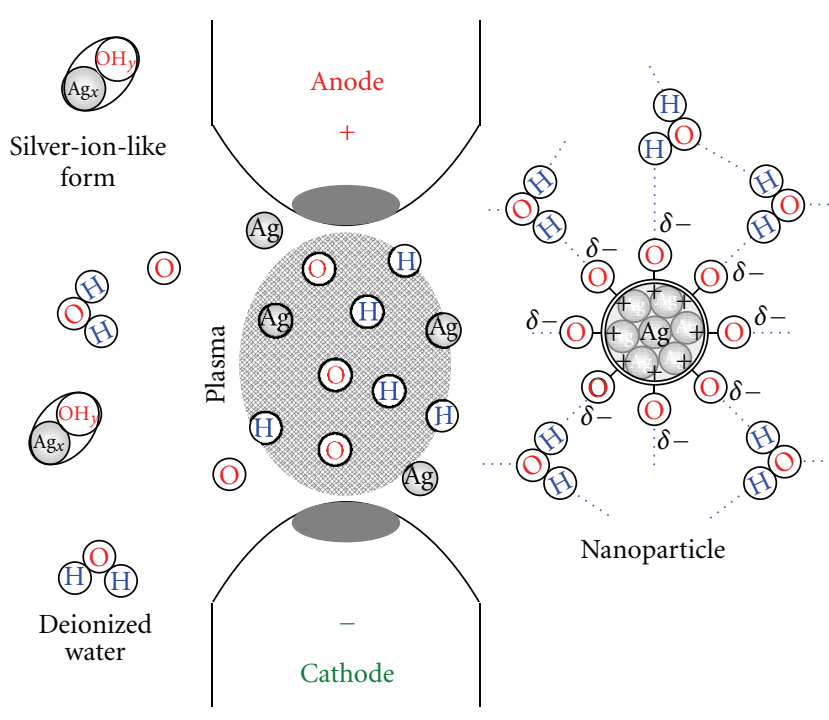

FIgURE 5: Plasma and electrical discharge.

to be 11.2 and $11.4 \mathrm{ppm}$, respectively. These results suggest that the concentration of suspended metallic Ag nanoparticle in SNPS was approximately $11 \mathrm{ppm}$.

In the fabrication process of SNPS, ionic Ag was produced as a by-product of the synthesis process of the metallic $\mathrm{Ag}$ nanoparticles. The spark discharge occurs as shown in Figure 5. Four individual effects simultaneously interact in the discharge process as follows:

(i) a strong electric field

(ii) a high plasma temperature

(iii) active $\mathrm{Ag}$ atoms being imparted from the $\mathrm{Ag}$ rod

(iv) hydrogen and oxygen atoms being imparted from water molecules

The Ag-ion-like compound dissolved in deionized water was formed when the reaction between the active atoms developed. Furthermore, during the bombardment of spark discharge, due to the hydrogen bond, the atomic oxygen can adhere to the surface of charged Ag nanoparticles (marked by the dash line in Figure 5). A steady colloid was formed due to the bond between water molecules and oxygen atoms on the surface of Ag nanoparticles.

Figures 6 and 7 illustrate the SEM images of Ag and $\mathrm{Au}$ nanoparticles, respectively. Several drops of Ag (or Au) colloid were deposited on a conductive silicon wafer, in 


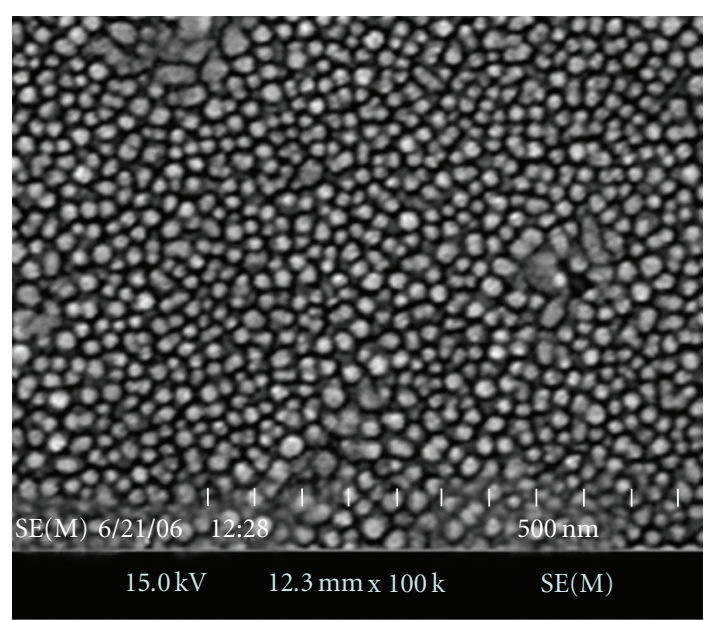

Figure 6: SEM image of prepared Ag nanoparticles.

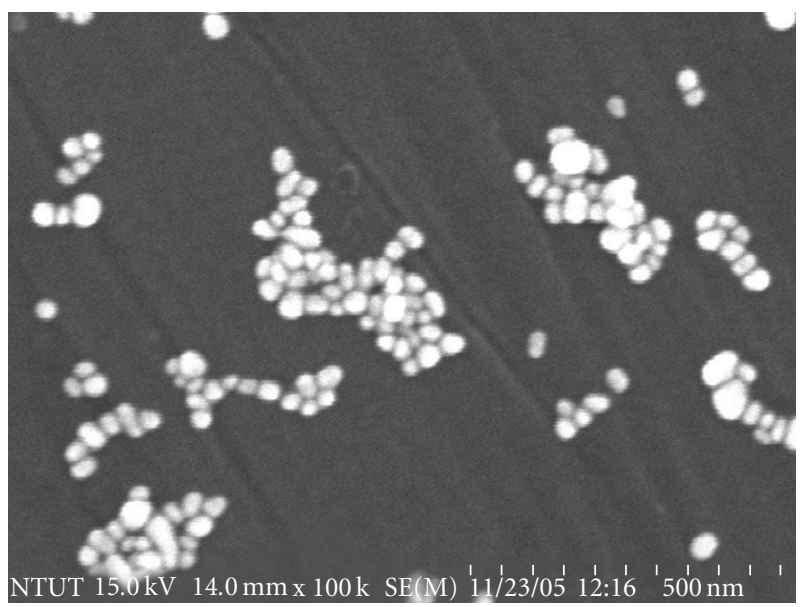

FIGURE 7: SEM image of prepared Au nanoparticles.

which the sample was then gently heated on a heating plate. The SEM image of the secondary electrons was then taken.

Figures 8 and 9 show the size distribution of $\mathrm{Ag}$ and $\mathrm{Au}$ nanoparticles which were calculated from the SEM image, respectively. The number of Ag particles with the size of $20 \mathrm{~nm} \pm 15 \mathrm{~nm}$ is dominant, while the number of $\mathrm{Au}$ particles with the size of $25 \mathrm{~nm} \pm 15 \mathrm{~nm}$ is principal.

The EDX spectrum shown in Figures 10 and 11 was obtained from the same sample of $\mathrm{Ag}$ and $\mathrm{Au}$ colloid, respectively. The EDX spectrum of Ag nanoparticles demonstrates the distinct presence of Ag peaks at 2.984 (AgL $\alpha 1$ ), 3.151 (Ag-L $\beta 1), 3.348$ (Ag-L $\beta 2), 3.52 \mathrm{keV}$ (Ag-Lg1) and $2.644 \mathrm{keV}$ (Ag-L1), while the EDX spectrum of $\mathrm{Au}$ nanoparticles demonstrates the distinct presence of Au peaks at 1.87, $2.1213(\mathrm{Au}-\mathrm{M} \alpha), 2.149(\mathrm{Au}-\mathrm{K} \beta 1)$ and $2.205 \mathrm{keV}(\mathrm{Au}-$ $\mathrm{M} \beta$ ). Some differences exist between the EDX spectra of Ag and Au nanoparticles as a layer of Au was coated on the SEM sample before performing the SEM analysis followed by the EDX spectrum test. In addition, the Si peak at $1.7398 \mathrm{keV}$ (Si$\mathrm{K} \alpha$ ) can be also found due to the presence of the silicon wafer which was used as a support for Ag and Au nanoparticles.

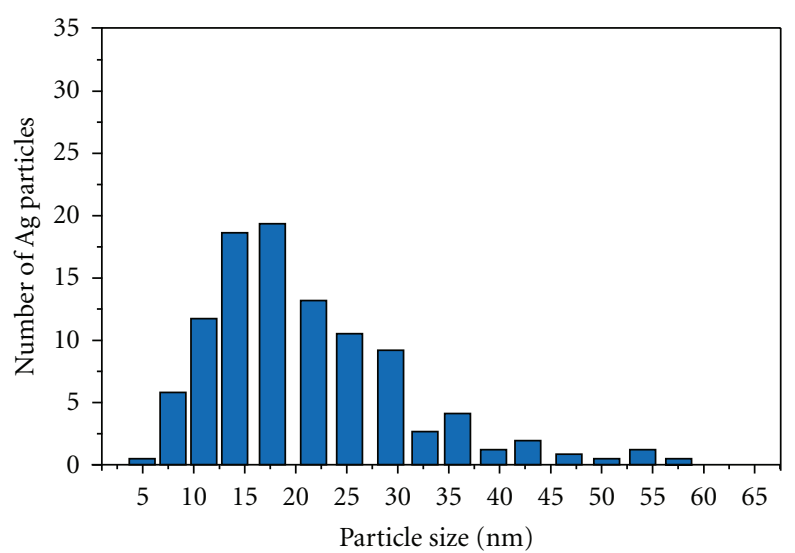

Figure 8: Size distribution of prepared Ag nanoparticles.

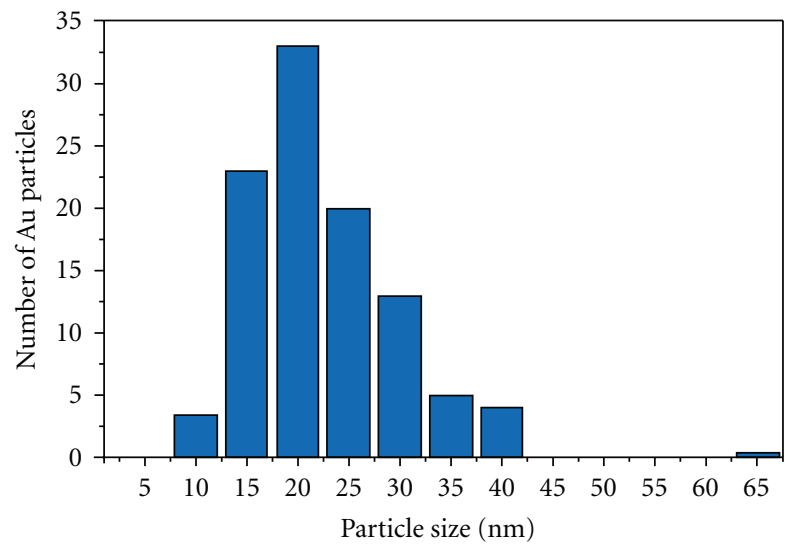

FIGURE 9: Size distribution of prepared Au nanoparticles.

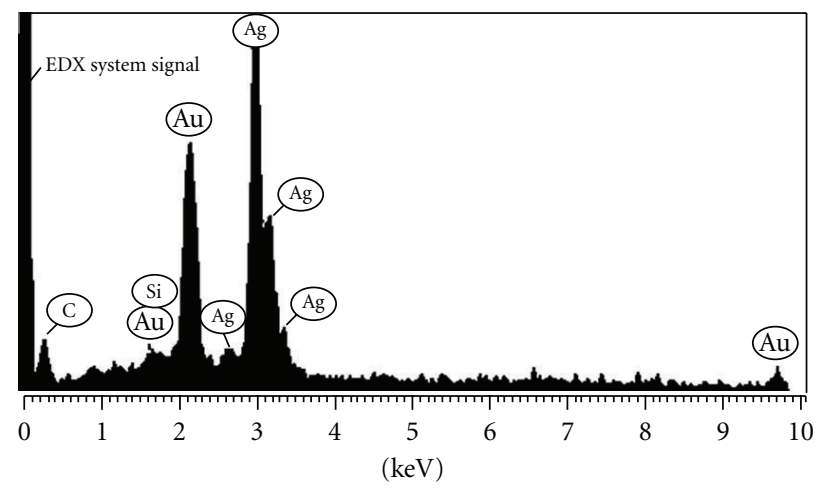

Full scale 198 cts cursor: $0.104 \mathrm{keV}$ ( $27 \mathrm{cts})$

Figure 10: EDX spectrum of Ag nanoparticles deposited.

The maximum Zeta potential of the aqueous Ag and $\mathrm{Au}$ colloid was found reaching at approximately $-45 \mathrm{mV}$ and $-35 \mathrm{mV}$, respectively. Figures 12 and 13 demonstrate the negatively charged $\mathrm{Ag}$ and Au nanoparticles in water, respectively. The $\mathrm{Ag}$ (or $\mathrm{Au}$ ) particles dispersed in water were negatively charged due to their ionic characteristics of Ag (or Au) micelles. The repulsive electrostatic forces existing 


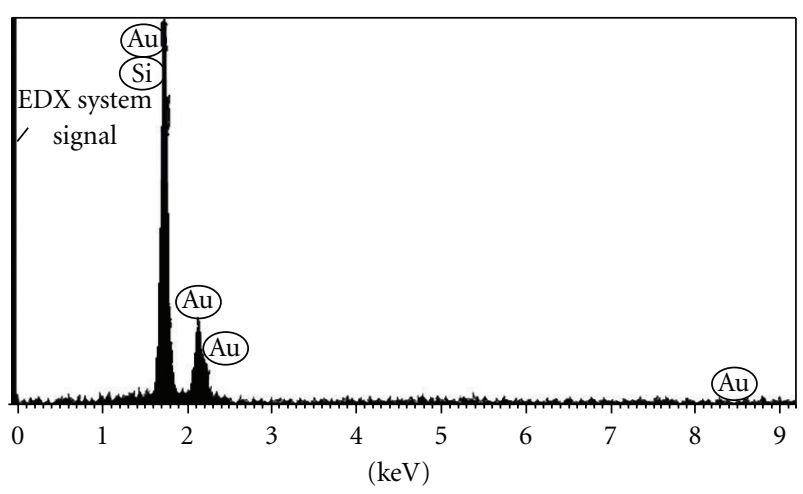

Full scale 259 cts cursor: $0.000 \mathrm{keV}$

FIGURE 11: EDX spectrum of Au nanoparticles deposited.

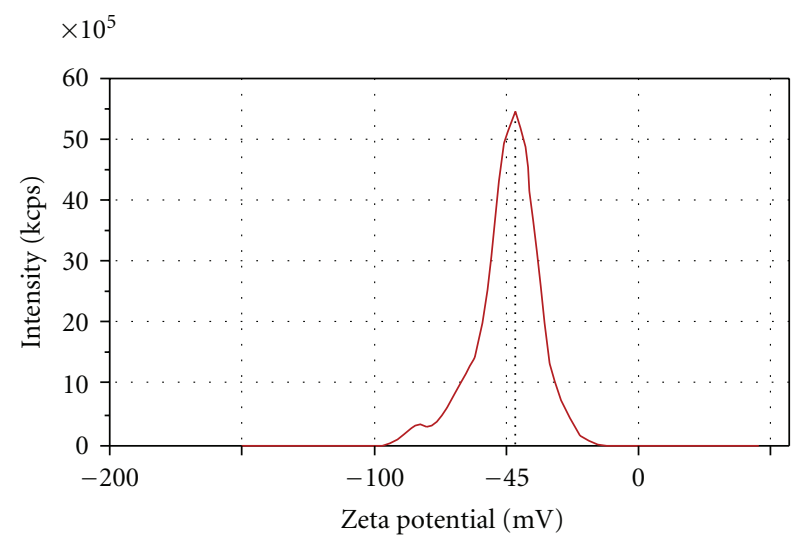

Figure 12: Zeta potential of the aqueous Ag colloid.

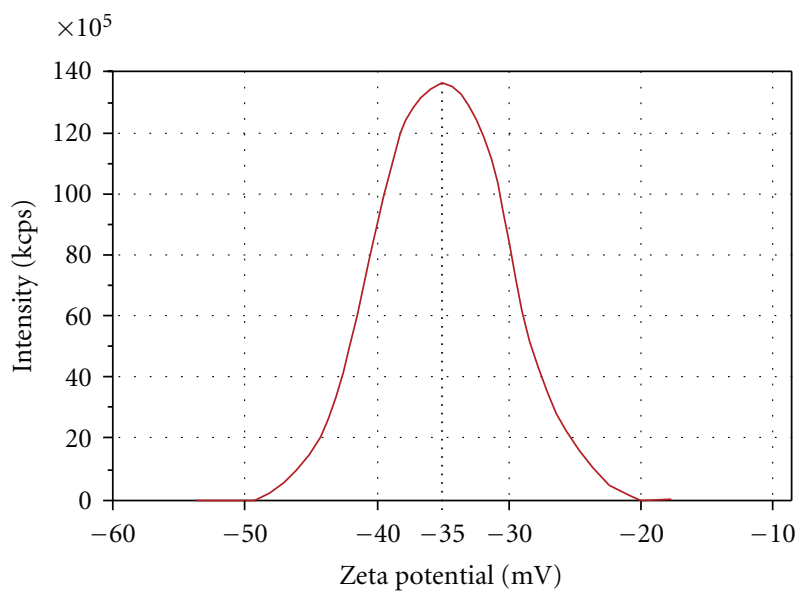

Figure 13: Zeta potential of the aqueous Au colloid.

between $\mathrm{Ag}$ (or $\mathrm{Au}$ ) nanoparticles protect them against the agglomeration and sedimentation in water suspension.

The UV-VIS absorption spectra of Ag and Au nanoparticles suspension are shown in Figures 14 and 15, respectively. A maximum absorbance in the region of approximately $396 \mathrm{~nm}$ (for $\mathrm{Ag}$ ) and $525 \mathrm{~nm}$ (for $\mathrm{Au}$ ), respectively, can be also found in other references [15-17] and [18, 19], respectively.

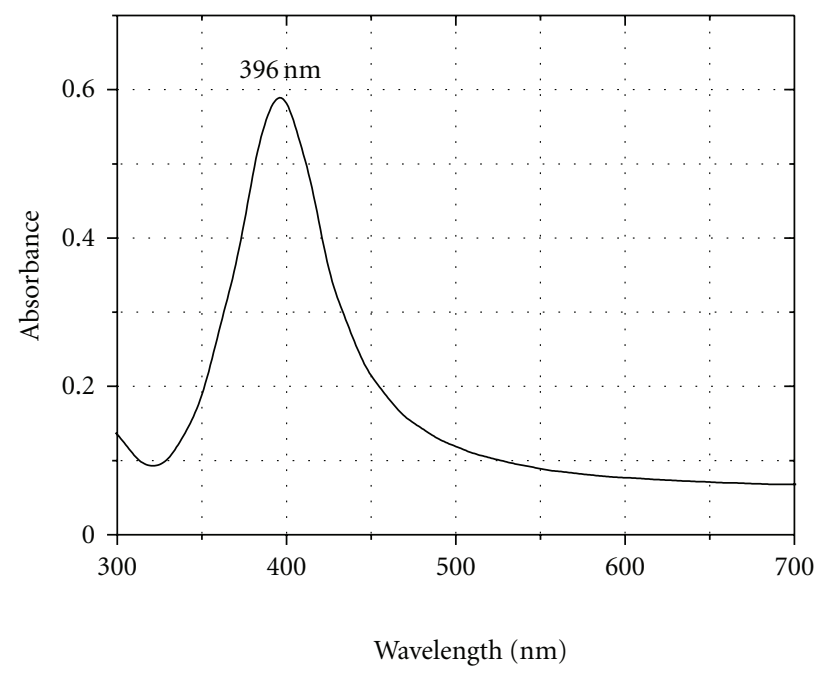

FIGURE 14: UV-VIS absorption spectra of the aqueous Ag colloid.

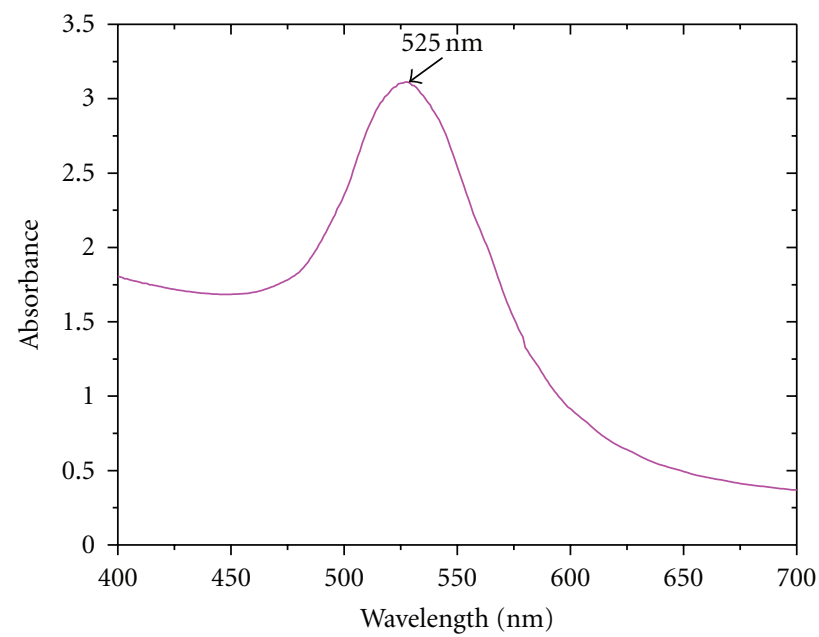

FIGURE 15: UV-VIS absorption spectra of the aqueous Au colloid.

The process of water decomposition (electrolysis) can be also observed during the production of $\mathrm{Ag}$ or Au nanoparticles by arc discharge. Gaseous hydrogen and oxygen appeared in water with a form of small bubbles. They were then partly dissolved in water. After that, hydrogen and oxygen started interacting with $\mathrm{Ag}$ (or $\mathrm{Au}$ ) nanoparticles which was newly prepared. Since hydrogen (with a form of molecular or atomic) cannot continue to be adsorbed on the Au surface at room temperature [20-22], it was ultimately removed from the water suspension and became the gas phase. Meanwhile, at room temperature, oxygen can be absorbed on the $\mathrm{Au}$ surface [23-25]. The negatively charged surface of Ag (or $\mathrm{Au}$ ) nanoparticles which have been injected with electrons by the cathode during arc discharge was saturated by the atomic oxygen which can create hydrogen bonds with water particles in water environment.

Consequently, the negatively charged $\mathrm{Ag}$ (or $\mathrm{Au}$ ) nanoparticle micelles can be created in the water medium. The model of $\mathrm{Ag}$ and $\mathrm{Au}$ nanoparticle micelles is shown 


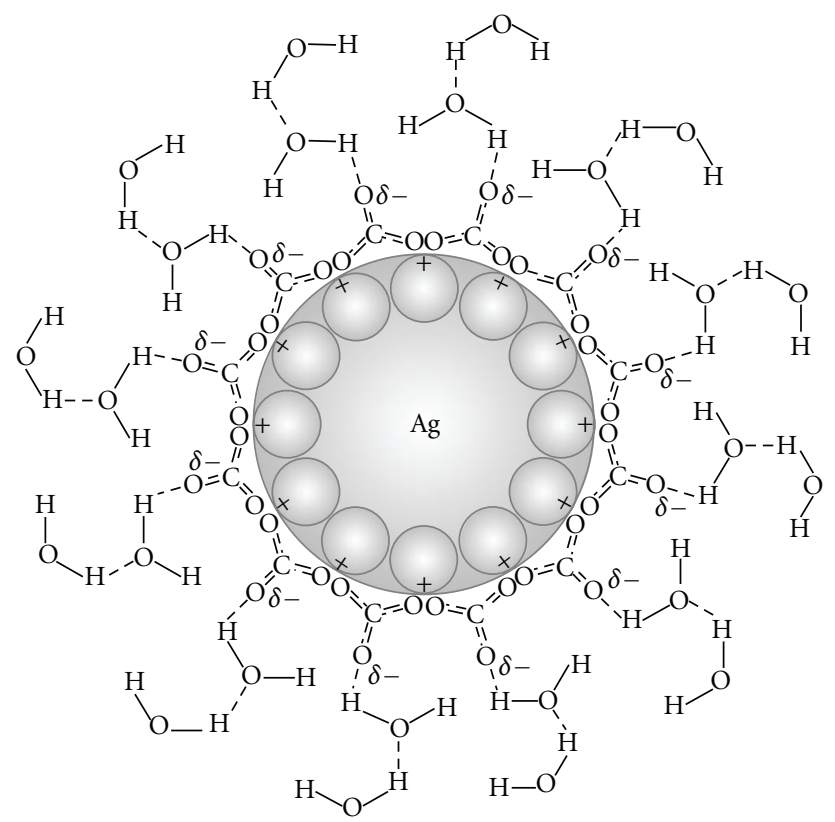

Figure 16: Model of Ag nanoparticle micelles.

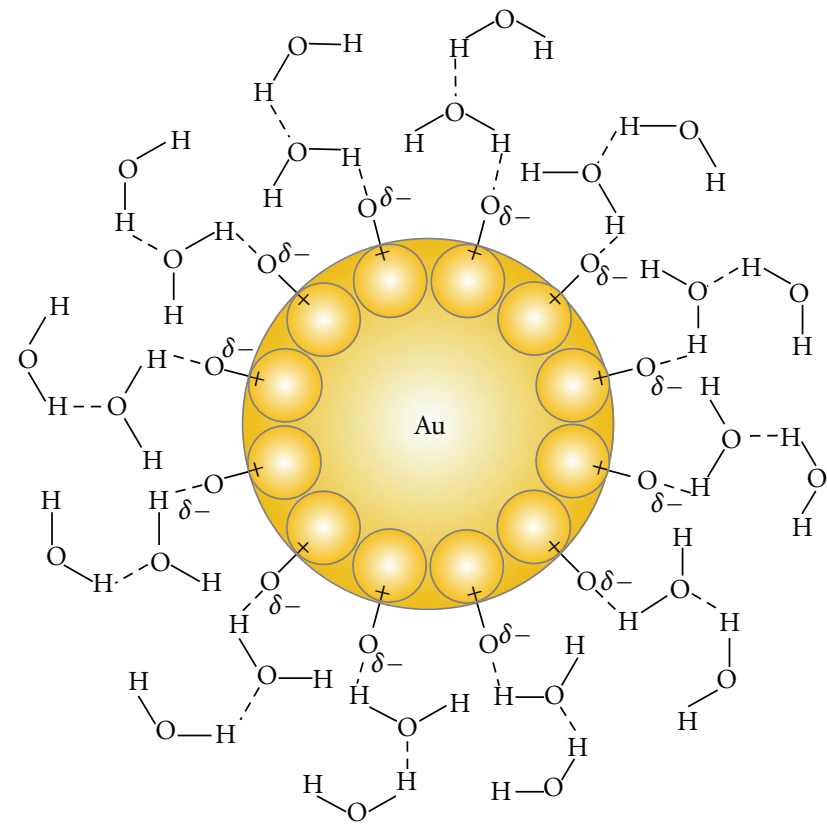

FIgURE 17: Model of Au nanoparticle micelles.

in Figures 16 and 17, respectively. The water molecules can bond with $\mathrm{Ag}$ (or $\mathrm{Au}$ ) nanoparticles due to hydrogen bonds which are represented by the dash lines. It is importantly noted that the negatively charged Ag (or $\mathrm{Au}$ ) nanoparticles which are surrounded by water molecules can create a stable suspension without adding any stabilizers and surfactants.

Meanwhile, during the arc discharge, the water molecules can dissociate into hydrogen, oxygen, and free radical hydroxides $(\mathrm{OH})$, during which the oxygen atoms are

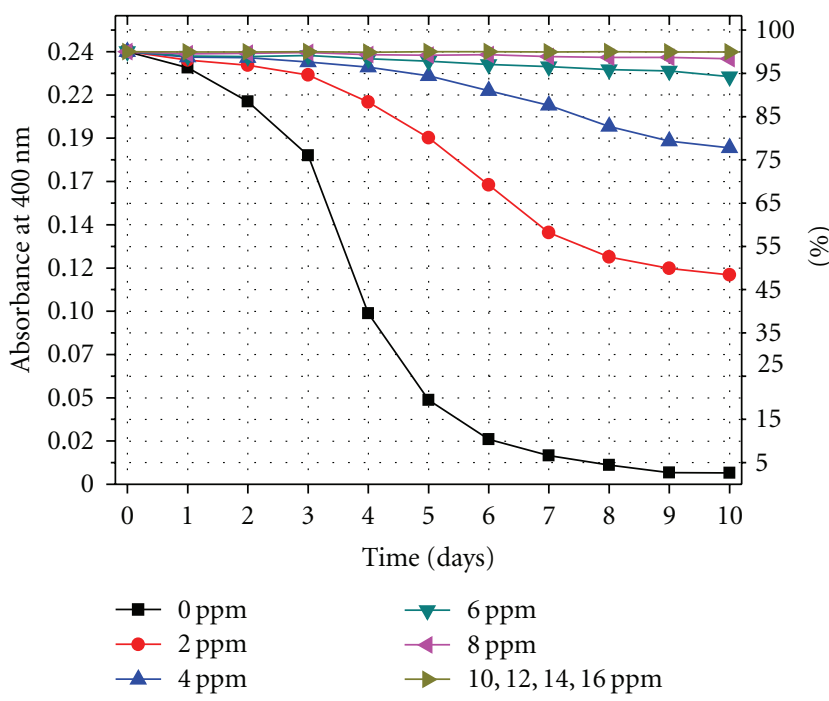

FIgURE 18: Tracking the absorption peak of CS samples with varying $\mathrm{Ag}+$ ion concentrations.

absorbed by the nano-Au surface. Therefore, this leads to the formation of hydrogen bond with the neighboring water molecules and supports, Au nanoparticles to be suspended in water, preventing agglomeration and sedimentation of the $\mathrm{Au}$ particles. Since $\mathrm{Au}$ is a noble metal, oxygen does not chemically react with Au. However, the bonding strength of oxygen adsorption on the prepared $\mathrm{Au}$ is only slightly lower than that of the energy of covalent bonding. In contrast to $\mathrm{Au}$, the nature of $\mathrm{Ag}$ is different from $\mathrm{Au}$ as $\mathrm{Ag}$ is of a subnoble metal. Although $\mathrm{Ag}$ is not easily oxidized, in the presence of a strong electric field, the dissolved $\mathrm{H}_{2} \mathrm{CO}_{3}$ (Dihydrogen Carbonate) in water can react with $\mathrm{Ag}$ and lead to the formation of $\mathrm{Ag}_{2} \mathrm{CO}_{3}(\mathrm{Ag}$ Carbonate), which is a partially soluble compound. During the process, the dissociated $\mathrm{CO}_{3}$ near the $\mathrm{Ag}$ surface can lead to the dissolution of micro-nano $\mathrm{Ag}$ in the water solution.

When the concentration of $\mathrm{Ag}+$ ions is over $10 \mathrm{ppm}$ as shown in Figure 18, the absorption peak of the AgNPs can maintain its value indefinitely without change. This suggests that the concentration of $\mathrm{Ag}_{2} \mathrm{CO}_{3}$ is thus demonstrated to be linked to the suspensivity of AgNPs. When the concentration of Ag+ ions is higher than the threshold value, AgNPs can maintain a steady level of suspensivity.

One of the most promising applications of AgNPs is its bacteriacidal effect against Staphylococcus aureus.The results from the antimicrobial susceptibility tests suggest that a linear relationship exists between the concentration of silver ions and the diameter of the hollow region which depends on the attacking potency of the anibiotic. That is, the antibacterial potency of a solution is directly related to its level of silver ion concentration, as shown in Figure 19, and not to the AgNps which was assumed prior to the research. Extrapolating from this linear relationship, we can predict that the critical concentration of silver ions for producing an inhibitory effect is $18.5 \mathrm{ppm}$. 


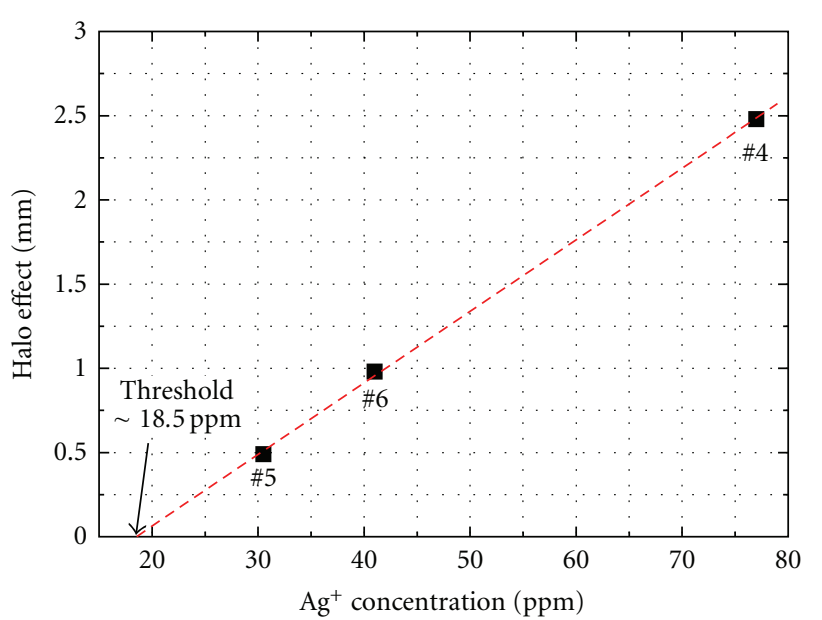

- $\mathrm{Ag}^{+}$concentration versus halo effect

Linear fit $\left(Y=-0.78734+0.04251^{*} X\right)$

FIGURE 19: Concentration of silver ions and inhibitory effect.

\section{Conclusions}

(1) The DC arc discharge method has been successfully developed for the production of Ag and Au nanoparticles.

(2) Ag and Au nanoparticles in water are characterized as a stable colloid without adding any stabilizers, as the concentration of $\mathrm{Ag}^{+}$ions is over $10 \mathrm{ppm}$, AgNPs can maintain its value indefinitely without change.

(3) The experimental result indicates that the prepared $\mathrm{Au}$ nanoparticles with their surfaces bonded by oxygen atoms are supported by the formation of hydrogen bond with the neighboring water molecules. This well explains that $\mathrm{Au}$ nanoparticles can suspend in water without agglomeration. The bonding strength of oxygen adsorption on the prepared $\mathrm{Au}$ is only slightly lower than that of the energy of covalent bonding.

(4) The prepared Ag nanoparticles react with the dissolved $\mathrm{H}_{2} \mathrm{CO}_{3}$ in water, leading to the formation of $\mathrm{Ag}_{2} \mathrm{CO}_{3}$ (Ag Carbonate). The dissociated $\mathrm{CO}_{3}$ near the Ag surface can lead to the dissolution of $\mathrm{Ag}$ nanoparticles in the water solution.

\section{Acknowledgment}

The authors would like to thank the National Science Council (NSC) of Taiwan for financial support.

\section{References}

[1] J. Rungby, "The silver nitrate prophylaxis of Crede causes silver deposition in the cornea of experimental animals," Experimental Eye Research, vol. 42, no. 1, pp. 93-94, 1986.

[2] S. R. Norrby, C. E. Nord, and R. Finch, "Lack of development of new antimicrobial drugs: a potential serious threat to public health," The Lancet Infectious Diseases, vol. 5, no. 2, pp. 115119, 2005.

[3] F. C. Tenover, "The real vancomycin-resistant Staphylococcus aureus has arrived," Clinical Microbiology Newsletter, vol. 27, no. 5, pp. 35-40, 2005.

[4] N. Ichinose, Y. Ozaki, and S. Kashu, Superfine Particle Technology, Springer, New York, NY, USA, 1992.

[5] Y. Li, P. Leung, L. Yao, Q. W. Song, and E. Newton, "Antimicrobial effect of surgical masks coated with nanoparticles," Journal of Hospital Infection, vol. 62, no. 1, pp. 58-63, 2006.

[6] J.-K. Lung, J.-C. Huang, D.-C. Tien et al., "Preparation of gold nanoparticles by arc discharge in water," Journal of Alloys and Compounds, vol. 434-435, pp. 655-658, 2007.

[7] C.-H. Lo, T.-T. Tsung, and H.-M. Lin, "Preparation of silver nanofluid by the submerged arc nanoparticle synthesis system (SANSS)," Journal of Alloys and Compounds, vol. 434-435, pp. 659-662, 2007.

[8] Liang-Chia Chen, "Investigation on morphology measurement and evaluation of $\mathrm{TiO}_{2}$ nanoparticles synthesized by SANSS," Journal of Alloys and Compounds, vol. 483, no. 1-2, pp. 366-370, 2009.

[9] Liang-Chia Chen, "Preparation of $\mathrm{TiO}_{2}$ nanoparticles by submerged arc nanoparticle synthesis system ," Journal of Alloys and Compounds, vol. 495, no. 2, pp. 476-480, 2010.

[10] D. C. Tien, C. Y. Liao, Y. C. Chen et al., "Ionic concentration of sanns colloidal silver and antimicrobial effect on Staphylococcus aureus," in Proceedings of the International Symposium on Biomedical Engineering (ISOBME '06), Taipei, Taiwan, December 2006.

[11] Q. L. Feng, J. Wu, G. Q. Chen, F. Z. Cui, T. N. Kim, and J. O. Kim, "A mechanistic study of the antibacterial effect of silver ions on Escherichia coli and Staphylococcus aureus," Journal of Biomedical Materials Research, vol. 52, no. 4, pp. 662-668, 2000.

[12] M. H. Magnusson, K. Deppert, J.-O. Malm, J.-O. Bovin, and L. Samuelson, "Size-selected gold nanoparticles by aerosol technology," Nanostructured Materials, vol. 12, no. 1, pp. 4548, 1999.

[13] W. M. Tolles, "Nanoscience and nanotechnology in Europe," Nanotechnology, vol. 7, no. 2, pp. 59-105, 1996.

[14] T.-T. Tsung, H. Chang, L.-C. Chen, L.-L. Han, C.-H. Lo, and M.-K. Liu, "Development of pressure control technique of an arc-submerged nanoparticle synthesis system (ASNSS) for copper nanoparticle fabrication," Materials Transactions, vol. 44, no. 6, pp. 1138-1142, 2003.

[15] A. Henglein, "Physicochemical properties of small metal particles in solution: "Microelectrode" reactions, chemisorption, composite metal particles, and the atom-to-metal transition," Journal of Physical Chemistry, vol. 97, no. 21, pp. 5457-5471, 1993.

[16] J. J. Storhoff, A. A. Lazarides, R. C. Mucic, C. A. Mirkin, R. L. Letsinger, and G. C. Schatz, "What controls the optical properties of DNA-linked gold nanoparticle assemblies?" Journal of the American Chemical Society, vol. 122, no. 19, pp. 4640-4650, 2000.

[17] S. O. Obare, R. E. Hollowell, and C. J. Murphy, "Sensing strategy for lithium ion based on gold nanoparticles," Langmuir, vol. 18, no. 26, pp. 10407-10410, 2002.

[18] J. J. Storhoff, A. A. Lazarides, R. C. Mucic, C. A. Mirkin, R. L. Letsinger, and G. C. Schatz, "What controls the optical properties of DNA-linked gold nanoparticle assemblies?" Journal of the American Chemical Society, vol. 122, no. 19, pp. 4640-4650, 2000. 
[19] S. O. Obare, R. E. Hollowell, and C. J. Murphy, "Sensing strategy for lithium ion based on gold nanoparticles," Langmuir, vol. 18, no. 26, pp. 10407-10410, 2002.

[20] L. Stobiński and R. Duś, "Atomic hydrogen adsorption on thin gold films,” Surface Science, vol. 269-270, pp. 383-388, 1992.

[21] L. Stobiński and R. Duś, "Atomic hydrogen solubility in thin gold films and its influence on hydrogen thermal desorption spectra from the surface," Applied Surface Science, vol. 62, no. 1-2, pp. 77-82, 1992.

[22] L. Stobiński, R. Nowakowski, and R. Duś, "Atomic hydrogen adsorption on thin discontinuous and continuous gold films_-similarities and differences," Vacuum, vol. 48, no. 3-4, pp. 203-207, 1997.

[23] N. Saliba, D. H. Parker, and B. E. Koel, "Adsorption of oxygen on $\mathrm{Au}(111)$ by exposure to ozone," Surface Science, vol. 410, no. 2-3, pp. 270-282, 1998.

[24] A. Franceschetti, S. J. Pennycook, and S. T. Pantelides, "Oxygen chemisorption on Au nanoparticles," Chemical Physics Letters, vol. 374, no. 5-6, pp. 471-475, 2003.

[25] S. D. Puckett, J. A. Heuser, J. D. Keith, W. U. Spendel, and G. E. Pacey, "Interaction of ozone with gold nanoparticles," Talanta, vol. 66, no. 5, pp. 1242-1246, 2005. 

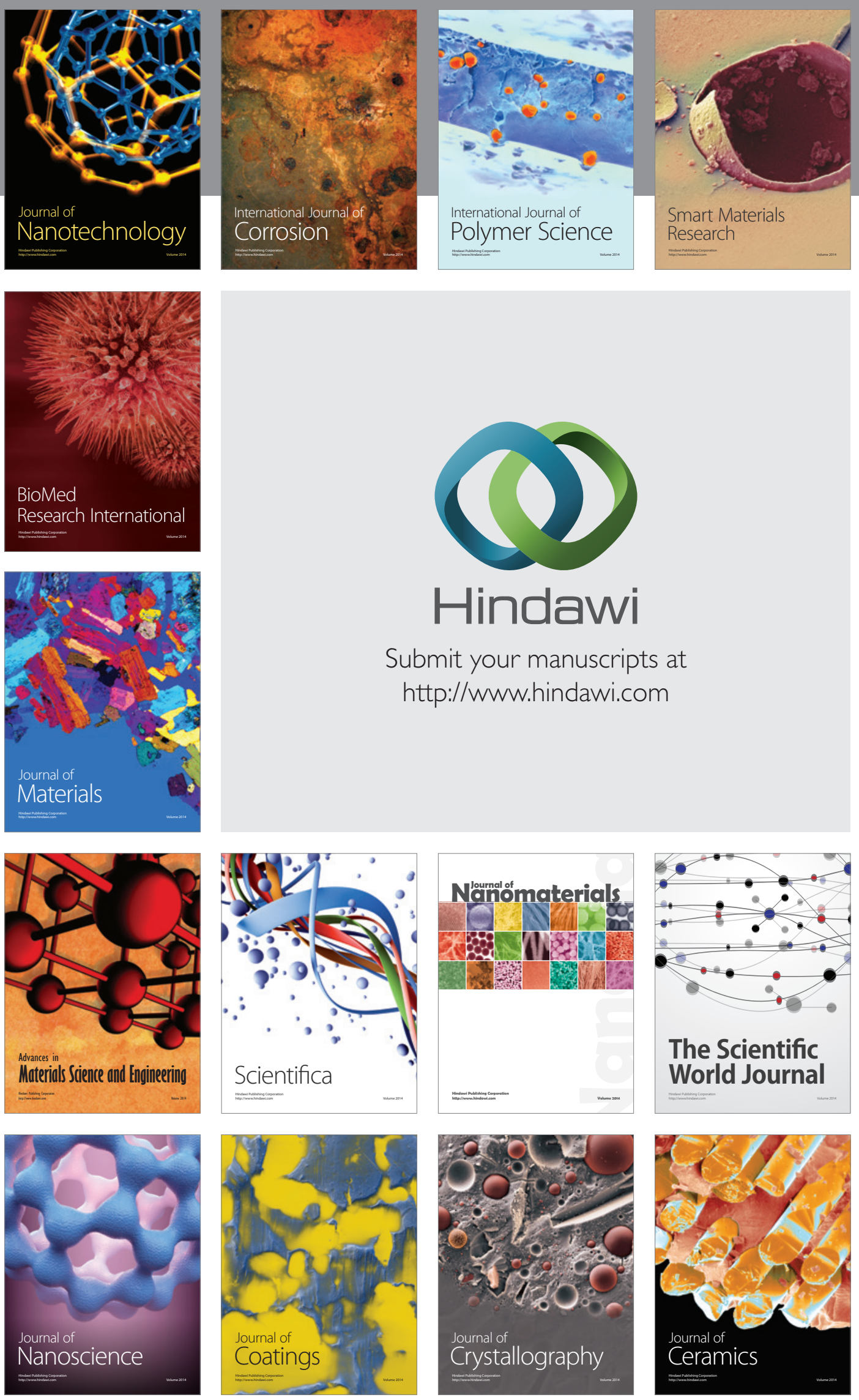

The Scientific World Journal

Submit your manuscripts at

http://www.hindawi.com

\section{World Journal}

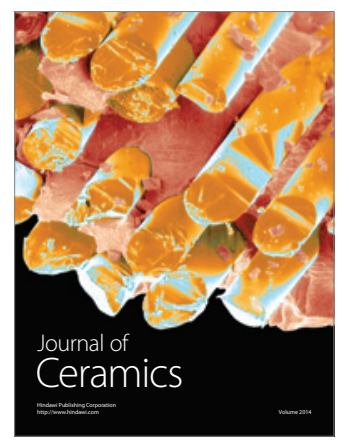

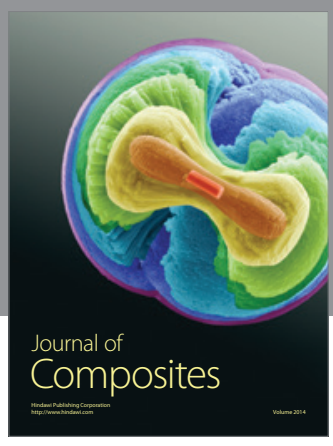
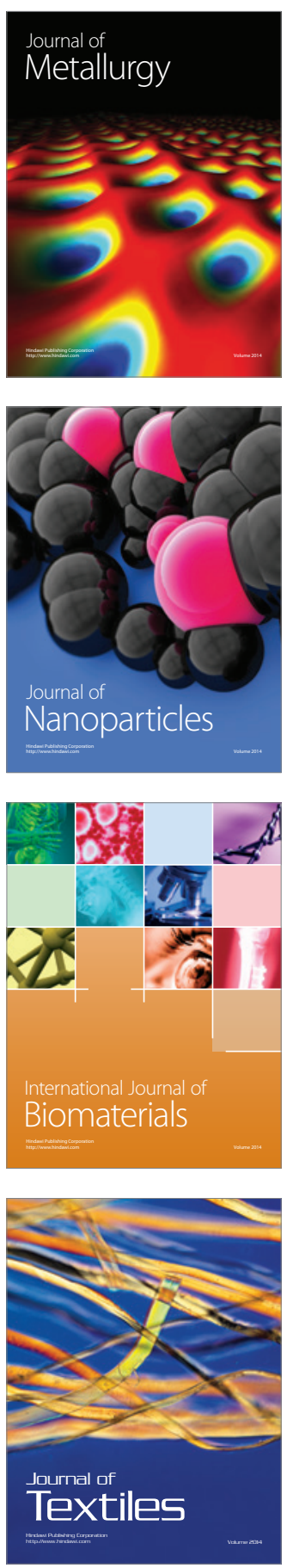